\title{
Cell-based Screening for Identification of Novel Vanadium Complexes with Multidirectional Activity Relative to Cells Associated with Metabolic Disorders
}

\author{
Grzegorz Kazeka, *, Monika Głuch-Lutwin ${ }^{\mathrm{b}}$, Barbara Mordyl', Elżbieta Menaszek \\ Janusz Szklarzewicz ${ }^{d}$, Ryszard Grybośd, Monika Papieżc \\ ${ }^{a}$ Department of Pharmacological Screening, Chair of Pharmacodynamics, Faculty of Pharmacy, Jagiellonian University Collegium \\ Medicum, Medyczna 9, 30-688 Krakow, Poland \\ ${ }^{\mathrm{b}}$ Department of Radioligands, Chair of Pharmacobiology, Faculty of Pharmacy, Jagiellonian University Collegium Medicum, \\ Medyczna 9, 30-688 Krakow, Poland \\ ' Department of Cytobiology, Chair of Pharmacobiology, Faculty of Pharmacy, Jagiellonian University \\ Collegium Medicum, Medyczna 9, 30-688 Krakow, Poland \\ ' Faculty of Chemistry, Jagiellonian University, Gronostajowa 2, 30-387, Krakow, Poland
}

\section{Article history:}

Received 20 December 2018

Received in revised form

20 December 2018

Accepted 14 March 2019

Available online 14 March 2019

\begin{abstract}
In this study, 110 newly synthesized vanadium complexes from different structural groups were screened in three cell-based models representing the main target tissues for anti-diabetic drugs. In glucose utilization in $\mathrm{C} 2 \mathrm{C} 12$ myocyte experiments, $93 \%$ of vanadium complexes were shown to have equal or greater activity than bis(maltolato)oxovanadium(IV) (BMOV), the methyl analog of bis(ethylmaltolato)oxovanadium(IV) (BEOV) which has been tested in clinical trials. Moreover, $49 \%$ and $50 \%$ of these complexes were shown to have equal or greater activity than BMOV in lipid accumulation in 3T3-L1 adipocytes and insulin secretion in RINm5F beta cell experiments, respectively. These results were the basis for the selection of compounds for the subsequent steps in the characterization of anti-diabetic properties. This study provides strong support for the application of screening cell-based assays with a phenotypic approach for the discovery of novel anti-diabetic drugs from the vanadium complex class. This is especially desirable due to the multiple and not fully defined mechanisms of action vanadium compounds.
\end{abstract}

Keywords: vanadium complexes, cell-based screening, anti-diabetic activity

\section{Introduction}

Diabetes is the 7th the most common of death worldwide [1]. Currently, 14 classes of drugs are available to treat type 2 diabetes mellitus, but only $36 \%$ of patients with type 2 diabetes achieve glycemic control with currently available therapies. Therefore, new treatment options are desperately needed, especially against various metabolic disturbances and diseases such as insulin resistance, glucose intolerance, pre-diabetes and non-alcoholic fatty liver disease [2]. Unfortunately, there are no approved medications and therapeutic interventions in these states are not well established [3].

The clinical use of vanadium in diabetes has occurred for over one hundred years and the current state of knowledge about the mechanisms of action of vanadium compounds and complexes and evidence of their pharmacological effectiveness means that they are an interesting and promising object for research [4].

The best known and most widely described mechanism of action of vanadium and its complexes is inhibition of protein tyrosine phosphatases, especially PTP1B. This leads to the

*Corresponding author: grzegorz.kazek@uj.edu.pl maintenance of the phosphorylated state of the insulin receptor and thus to upstreaming signaling analogous to the action of the insulin hormone. In a subsequent multi-step process, the glucose transporters are activated and cellular glucose uptake is then activated [5, 6, 7]. However, the importance of PTP1B inhibition as a key mechanism for vanadium does not limit the long list of identified molecular targets for vanadium action. Other enzymes (mostly phosphatases and kinases) in the glucose uptake pathway have been considered as targets; however, the insulin-like effects of vanadium remain still not fully answered $[8,9]$.

Among the main therapeutic strategies for treating type 2 diabetes are increasing insulin sensitivity (insulin sensitizers) and increasing insulin secretion (insulin secretagogues). Treating insulin resistance includes two mechanisms: activation of peroxisome proliferator-activated receptors (PPARs) such as thiazolidinediones (e.g., rosiglitazone and pioglitazone); and AMPK-activated protein kinase (AMPK) such as metformin. These two classes of drugs are the most commonly used medications for the treatment of type 2 diabetes. Anti-hyperglycemic drugs such as sulfonylureas and meglitinides increase insulin secretion from pancreatic beta-cells [10, 11, 12, 13]. 
The molecular mechanisms of the pharmacological effects of vanadium complexes involve multiple mechanisms which are identical with some therapeutic targets in the current classification of diabetes according to their molecular group and signaling molecules [14]. The mechanisms of the anti-diabetic actions of vanadium compounds include, in addition to the mentioned inhibition of tyrosine phosphatases, activation of numerous signaling pathways and transcription factors - AMPK, PI3KPKB-GSK-3ß/Akt-mTOR, NF-кB, MAPK (MEK1/2-ERK) and elevation of PPAR $\gamma$ levels [15, 16; reviewed in 4, 9, 17]. In addition to the effects on the metabolism of carbohydrates and lipids, vanadium complexes mediate regeneration of pancreatic $\beta$-cells which increase insulin production $[18,19]$.

Since vanadium complexes exert their wide range of metabolic effects via multiple mechanisms, in testing the anti-diabetic activity of vanadium compounds, it may not be sufficient to focus on a single mechanism, i.e. PTP1B inhibition [17]. The most appropriate research approach for the identification of novel compounds for therapeutic areas with complex disease pathomechanisms or where the compounds show activity against multiple molecular targets is an approach based on a phenotypic screening paradigm. These cell-based screens provide a substantial amount of biological information, such as the ability of a compound to ameliorate the phenotype of a intact cellular disease model, such as inhibition of a biological process, morphological or structural changes. They might provide direct evidence of efficacy, regardless of the intracellular molecular target $[20,21]$. Cell-based assays are able to examine the interaction between target and compounds in a cellular context in an extracellular environment similar to body fluids, and phenotypic screens can give important information about tested molecule penetration into intact cells, which seems to be particularly important in the context of interchange of chelators in extracellular and intracellular body media ("speciation") [9].

In this study, screening assays were conducted with the use of cellular models corresponding to the main cellular pharmacological targets associated with metabolic disturbances in diabetes and other metabolic disorders. Our laboratory has adapted and validated models described and used in vanadium activity assessment including: glucose utilization (consumption) in C2C12 myocytes [22, 23], lipid accumulation in 3T3-L1 adipocytes [24, 25, 26, 27] and insulin secretion in RINm5F beta-cells $[28,29]$. These experiments were used in the assessment of the anti-diabetic activity of vanadium complexes.

The level of glucose consumption by cells is the result of the transport of glucose to the cells and the degree of activation of intracellular metabolic processes; therefore, these assays best assess the influence of compounds acting on various mechanisms. Insulin plays an essential role in glucose homeostasis by increasing its storage or utilization by regulating the transport of glucose into the cell. Glucose transporter type 4 (Glut4) plays a fundamental role in glucose utilization in muscle and, upon stimulation by insulin, increases glucose transport into the cells. This is critical for the maintenance of glucose homeostasis and normal blood glucose level [30]. Adipose tissue and cells represent the targets of first choice for the development of cell-based assay systems for the insulin-like activity of compounds. This assay measures the cellular triglyceride level as an end-point readout and has the advantage of capturing the lipid lowering efficacy of potential candidates at different sites in lipid metabolic pathways [31]. Functional insulin-secreting pancreatic $\beta$ cells are used in the study of targets and drugs to promote insulin secretion [32]. Insulin resistance causes a rise in insulin secretion in a compensation mechanism leading to pancreatic beta cell stress and damage with a progressive decrease in insulin secretion and subsequent hyperglycemia [33].

Following validation by a series of biochemical and pharmacological tests, these three models were applied to screen over one hundred vanadium complexes from different structural groups. The purpose of this study stage was the selection of the most active new vanadium complexes as potential compounds for metabolic disorders. Reference compounds and drugs approved in diabetes treatment, the inorganic vanadium compound vanadyl sulfate $\left(\mathrm{VOSO}_{4}\right)$ and vanadium complex bis(maltolato)oxovanadium(IV) (BMOV), a methyl analog of ethylmaltolate (BEOV) which has advanced to phase II clinical trials [34] were used for comparations of biological activity. We used an approach based on high-throughput screening (HTS) methods and we adapted this strategy for academia-based projects in drug discovery with a small number of test compounds. In the current HTS data analysis, an activity cutoff value is set to select a certain number of compounds whose tested activities are greater than this threshold. In our study, the initial threshold values were the results for BMOV, because our goal was to discover complexes better than this well-studied and clinically tested vanadium complex.

\section{Materials and Methods}

\section{Chemical structure of tested vanadium complexes}

The vanadium complexes that have been subjected to pharmacological activity assays were synthetized in the Faculty of Chemistry, Jagiellonian University. They represent vanadium complexes (III, IV and V) with Shiff bases with donor atoms ONO. In the general, simplified formula [VX(ONO)y(L)n], X is oxygen or is absent and $\mathrm{L}$ is $\mathrm{L} 1$ or $\mathrm{L} 2$, wherein: $\mathrm{L} 1$ represents a halogen anion or a neutral or a deprotonated solvent molecule selected from the group consisting of C1-C12 alcohols, e.g. ethyl alcohol or methyl alcohol and/or water; L2 is a neutral or anionic ligand $\mathrm{NN}$, NO or OO-donor selected from the group consisting of: polypyridine, e.g. 2,2'-bipyridine (bpy), 1,10-phenanthroline (phen), pyrones, deprotonated 3-hydroxy-2-methyl-4-pyrone (mal-), quinoline, e.g. deprotonated 8-hydroxyquinoline (quin-) or pyridine carboxylic acids, e.g. deprotonated 2-picolinic acid. 
The letters $\mathrm{O}$ and $\mathrm{N}$ represent atom, through which the ligand is bound to the vanadium, means a triple-bond ligand of the general formula 1 (Figure 1) in the keto or enol form, neutral or deprotonated. R1, R2, R3, R4 independently represent hydrogen atom, fluorine atom, chlorine atom, bromine atom, iodine atom or a SO3, hydroxo, nitro, alkoxy, aryloxy, dialkylamino, alkyl or aryl group, wherein at least one of the R1, R2, R3, R4 substituents is different from hydrogen atom, R5 independently stands for hydrogen atom, alkyl or aryl group, R6 is a group selected from those given in Figure 2. In addition to these generally described complexes, several vanadium complexes with thioanilide amino acid derivatives has been tested in this study.<smiles>[R]C(=O)NN=C([R5])c1c([R4])c([R3])c([R2])c([R])c1O</smiles>

Figure 1. General structural formula 1 ciently high signal from the experimental setup in the absence of significant cytotoxic activity. Based on the results for BMOV and $\mathrm{VOSO}_{4}$, the concentration $100 \mu \mathrm{M}$ for 60 min incubation with pancreatic beta-cells (RINm5F) and the concentration $50 \mu \mathrm{M}$ in 24-hour incubations of myocytes $(\mathrm{C} 2 \mathrm{C} 12)$ and adipocytes (3T3-L1) were selected for the tests. All cytotoxicity tests were conducted at $50 \mu \mathrm{M}$ and 24-hour incubations. In other in vitro studies using cell models, the concentrations of vanadium compounds were up to $1 \mathrm{mM}[35,36]$.

\section{Glucose utilization in myocytes}

C2C12 cell line (ATCC CRL-1772), subclone of myoblasts from mouse muscles were cultured according to a standard protocol in DMEM supplemented with $10 \%$ fetal calf serum, $100 \mathrm{IU} /$ $\mathrm{mL}$ penicillin and $100 \mu \mathrm{g} / \mathrm{mL}$ streptomycin at $37^{\circ} \mathrm{C}$ in $5 \% \mathrm{CO}_{2}$. Cells were plated on a 96-well microplate and after reach confluency were differentiated in medium with $2 \%$ horse serum. After differentiation, the medium was changed for medium with $0.2 \%$ bovine serum albumin, $100 \mathrm{IU} / \mathrm{mL}$ penicillin, $100 \mu \mathrm{g} / \mathrm{mL}$ streptomycin and after 2 hours incubation the medium was changed<smiles>[R]c1ccc(C)cc1</smiles>

(A)<smiles>Cc1ccccc1O</smiles>

(B)<smiles>CCc1c#cccc1</smiles>

(C)<smiles>Cc1cc2ccccc2cc1O</smiles>

(D)<smiles>Cc1cccnc1</smiles>

(E)<smiles>CC(N)Cc1ccc(O)cc1</smiles><smiles>CCc1c[nH]c2ccccc12</smiles>

(F)

(G)

Figure 2. Substituents R6 in the formula 1<smiles>Cc1cc(-c2ccccc2)on1</smiles>

(H)

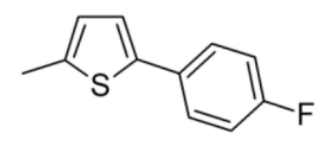

(I)

\section{Cell models and treatment}

All cell lines were obtained directly from ATCC (American Type Culture Collection). The passage number of cells used in the experiments was between 4 and 10 . The evaluation of the functional stability of the cell lines was conducted based on the results for control compounds, which were tested in each experimental series and compared with the results obtained in the process of validation and optimization of experimental models. Control compounds in all experiments were BMOV and $\mathrm{VOSO}_{4}$. In the experiments of glucose consumption and lipid accumulation and in the experiments of insulin secretion rosiglitazone and glibenclamide, respectively, were additionally tested. The concentrations of the control compounds were the same as those of the tested complexes.

The concentrations used in the studies were selected in the process of the validation of research models to ensure a suffi- for fresh medium containing vanadium complexes in a $50 \mu \mathrm{M}$ final concentration. After 24 hours incubation, supernatants were collected. Incubations of vanadium complexes with cells were performed in triplicate and each compound was tested in three to four independent experiments.

Glucose concentration was determined based on an enzymatic reaction with glucose oxidase and a final fluorometric detection reaction end product using an Amplex Red Glucose/Glucose Oxidase Kit (Invitrogen) according to the manufacturer's protocol. A total of $10 \mu \mathrm{L}$ supernatant was diluted in $50 \mathrm{mM}$ PBS pH 7.4 and $10 \mu \mathrm{L}$ reagents containing $4 \mathrm{U} / \mathrm{mL}$ glucose oxidase, 0.4 $\mathrm{U} / \mathrm{mL}$ horseradish peroxidase and $200 \mu \mathrm{M} 10$-acetyl-3,7-dihydroxyphenoxazine in $50 \mathrm{mM}$ PBS pH 7.4 was added to a 384well black microplate and incubated for 30 minutes at $37^{\circ} \mathrm{C}$. All assays were conducted in triplicate. Fluorescence signal was measured at an excitation in $530 \mathrm{~nm}$ and emission in $580 \mathrm{~nm}$ us- 
ing a multimodal microplate reader POLARStar Omega (BMG Labtech) and glucose concentration in samples was calculated in MARS Data Analysis Software based on glucose standards. Working range of calibration was $1.56-50 \mu \mathrm{M}$ with mean sensitivity (slope) 7465 and mean linear fit $\mathrm{R} 2=0.9962$. Glucose utilization was calculated as the differences between incubation medium without cells and medium with cells after incubation with the tested compound. Final results were expressed as the per cent of controls containing cells and solvent only as well as the per cent of results for BMOV.

\section{Insulin secretion experiments}

RINm5F cell line (ATCC CRL-11605), pancreatic beta-cells derived from rat islets of Largenhans were cultured according to a standard protocol in RPMI-1640 medium supplemented with $10 \%$ fetal bovine serum, $100 \mathrm{IU} / \mathrm{mL}$ penicillin and $100 \mu \mathrm{g} / \mathrm{mL}$ streptomycin at $37^{\circ} \mathrm{C}$ in $5 \% \mathrm{CO}_{2}$. For insulin secretion experiments, cells were seeded in 96-well plates and cultured for 5 days. The medium was then aspirated, the cells were washed three times with Krebs-Ringer-HEPES buffer with $0.5 \%$ bovine serum albumin. Cells were incubated at $37^{\circ} \mathrm{C}$ for $60 \mathrm{~min}$ in the above buffer including the tested vanadium complexes in a $100 \mu \mathrm{M}$ final concentration and then supernatants were collected. Incubations of vanadium complexes with cells were performed in triplicate and each compound was tested in three to five independent experiments.

Insulin concentration was determined based on an amplified luminescent proximity homogeneous assay with an AlphaLISA immunoassay kit (PerkinElmer) according to the manufacturer's protocol. A total of $5 \mu 1$ supernatant added to 384well dedicated microplate was incubated for $60 \mathrm{~min}$ at $23^{\circ} \mathrm{C}$ with AlphaLISA Anti-Insulin Acceptor beads $(10 \mu \mathrm{g} / \mathrm{mL}$ final $)$ and Biotinylated Antibody Anti-Insulin (1 nM final). Then, Streptavidin (SA)-coated Donor beads were added and incubated for 30 min at $23^{\circ} \mathrm{C}$ in the dark. All assays were conducted in triplicate. Alpha signal readings were performed using multimodal microplate reader POLARStar Omega (BMG Labtech) and insulin concentration in samples was calculated in MARS Data Analysis Software based on insulin standards. Dynamic range of analytical method was 26.6-100 000 pg/ml (0.8-3 000 $\mu \mathrm{IU} / \mathrm{ml})$. Working range of calibration in linear range was 207.5 $\mathrm{pg} / \mathrm{ml}-1.95 \mathrm{ng} / \mathrm{ml}(7.8-125 \mu \mathrm{IU} / \mathrm{ml})$ with mean sensitivity (slope) 1882 and mean linear fit R2=0.9780. Final results were expressed as the per cent of control containing cells and solvent only as well as the per cent of results for BMOV.

\section{Lipid accumulation in adipocytes}

3T3-L1 cell line (ATCC CRL-11605) derived from fibroblasts from mouse embryo tissue were cultured according to a standard protocol in DMEM medium supplemented with 10\% bovine calf serum, $100 \mathrm{IU} / \mathrm{mL}$ penicillin and $100 \mu \mathrm{g} / \mathrm{mL}$ streptomycin at $37^{\circ} \mathrm{C}$ in $5 \% \mathrm{CO}_{2}$. For lipid accumulation experiments, cells were seeded in 96-well poly-D-lysine coated plates and cultured to reach confluency. The medium was then switched to differentiation medium. After 48 hours incubation, the medium was changed for standard medium with human recombinant insulin and the tested vanadium complexes in a $50 \mu \mathrm{M}$ final concentration were added after 1 hour. Incubations of vanadium complexes with cells were performed in triplicate and each compound was tested in three to four independent experiments. After 24 hours of cell incubation with compounds, wells were washed with PBS with calcium and magnesium and $5 \mu \mathrm{L}$ AdipoRed reagent (Lonza) in $200 \mu \mathrm{l}$ PBS was added and the mixture was incubated for 10 minutes at $22^{\circ} \mathrm{C}$. The fluorescence signal proportional to lipid content in cells was measured at an excitation in $530 \mathrm{~nm}$ and emission in $550 \mathrm{~nm}$ using a multimodal microplate reader POLARStar Omega (BMG Labtech). Final results were expressed as the per cent of control containing cells and solvent only as well as the per cent of results for BMOV.

\section{Cytotoxicity testing}

A cytotoxicity assay was performed using PrestoBlue Cell Viability Reagent (ThermoFisher Scientific), a cell permeable resazurin-based reagent that functions as a cell viability indicator by using the reducing power of living cells (mitochondrial enzymes activity) to quantitatively measure the proliferation of cells. After 24-hours of incubation of compounds with $\mathrm{C} 2 \mathrm{C} 12$, 3T3-L1 and RINm5F cells prepared as described above, $10 \mu \mathrm{L}$ of PrestoBlue reagent was added to each well and the microplate was mixed on an orbital shaker. Plates were incubated for 20 min and the fluorescence intensity at $560 \mathrm{~nm}$ excitation and 590 $\mathrm{nm}$ emission was determined using a multi-mode microplate reader POLARstar Omega (BMG Labtech, Germany). The results were normalized to the control (cells with solvent only), wherein the intensity of fluorescence was taken as $100 \%$.

\section{Results and Discussion}

The presented results of cell-based screening of vanadium complexes showed that a large part of the tested compounds showed greater activity than BMOV (Figure 1-3), the methyl analog of ethylmaltolate (BEOV) which has been tested in clinical trials [34]. In glucose consumption assays in $\mathrm{C} 2 \mathrm{C} 12$ myocytes, 103 out of 110 tested compounds (93\%) showed greater activity than BMOV, and 28 of these complexes have activity greater than $150 \%$ of BMOV activity, and the most active complex showed activity at $290 \%$ of BMOV activity (Figure 3). Moreover, 54 out of $110(49 \%)$ vanadium complexes showed equal or greater activity than BMOV in lipid accumulation in 3T3$\mathrm{L} 1$ adipocytes, wherein the largest observed value is $164 \%$ of the activity BMOV (Figure 4). In the insulin secretion assay, 54 (50\%) vanadium complexes showed higher activity in RINm5F beta-cells than BMOV and the most active complex show the level of $150 \%$ of BMOV activity (Figure 5 ). 


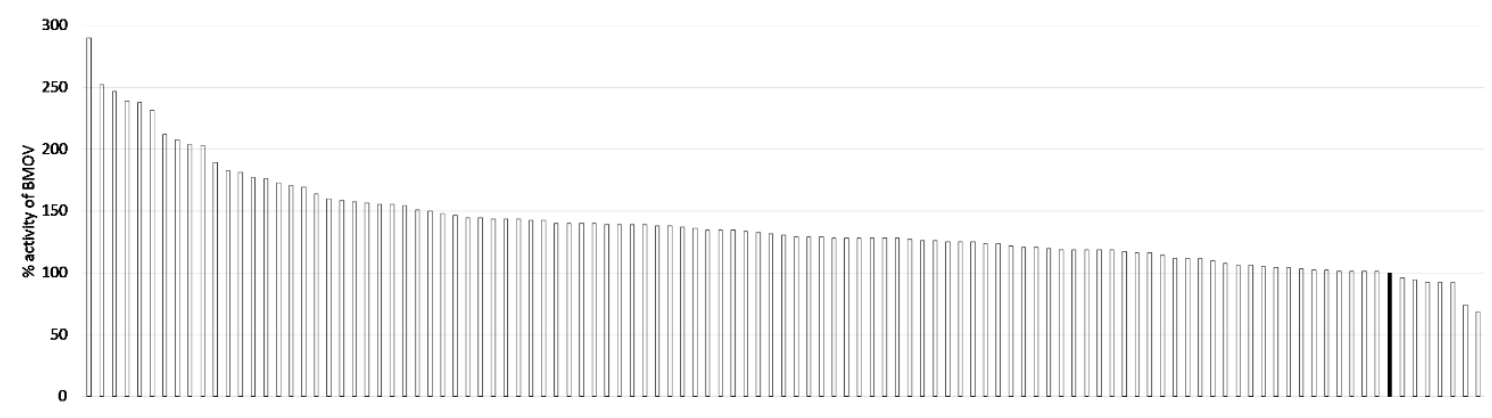

Figure 3. Glucose utilisation in $\mathrm{C} 2 \mathrm{C} 12$ myocytes screening activity results (24-hours incubation; final concentration of vanadium complexes $50 \mu \mathrm{M}$ ). Open bars graphs present ordered results for tested vanadium complexes as per cent of BMOV activity (filled bar)

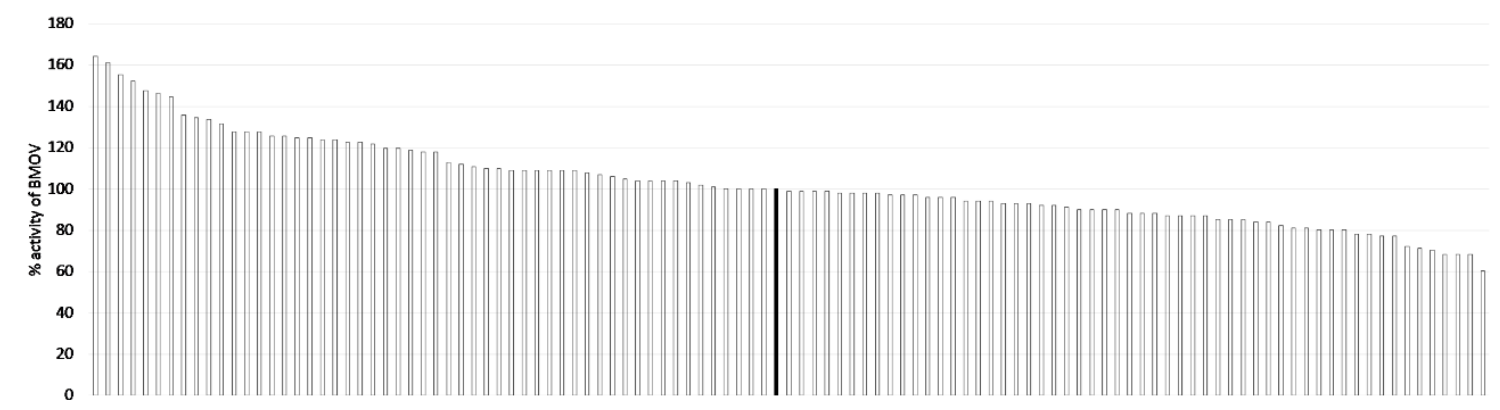

Figure 4. Lipid accumulation in 3T3-L1 adipocytes screening activity results (24-hours incubation; final concentration of vanadium complexes $50 \mu \mathrm{M}$ ). Open bars graphs present ordered results for tested vanadium complexes as per cent of BMOV activity (filled bar)

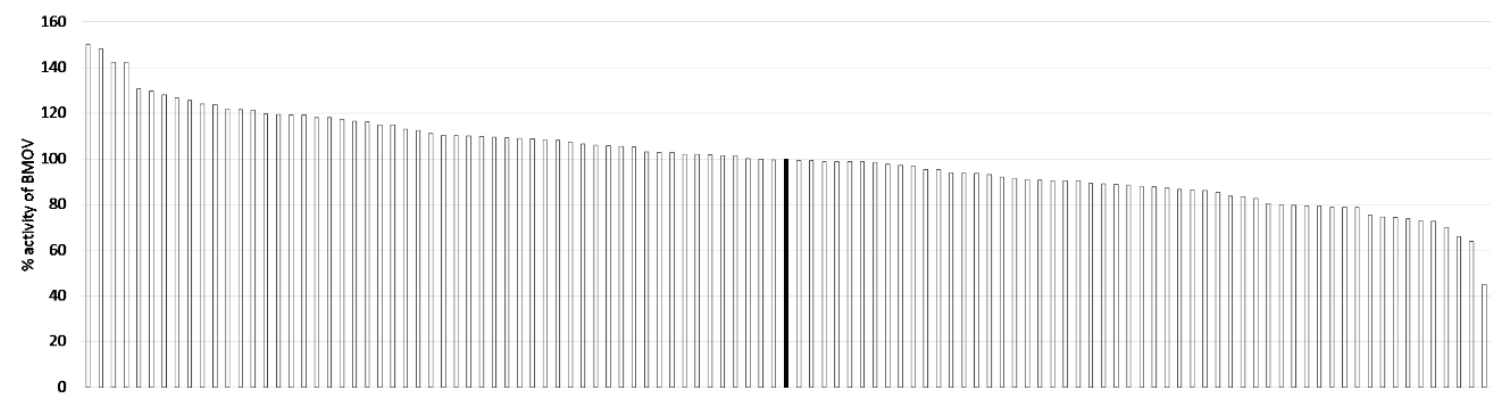

Figure 5. Insulin secretion in RINm5F beta cells screening activity results (60-minutes incubation; final concentration of vanadium complexes $100 \mu \mathrm{M}$ ). Open bars graphs present ordered results for tested vanadium complexes as per cent of BMOV activity (filled bar)

Based on the results presented in this study, those compounds were selected that showed high anti-diabetic activity and that simultaneously did not show significant toxicity in the same cellular models.

In the selection of complexes for further research, the profile of the anti-diabetic activity that complexes displayed for individual cell models was also identified. Table 1 shows examples of complexes illustrating high heterogeneity in cell activity pro- files, from selective action in terms of insulin secretion against RINm5F pancreatic beta-cells (complex VC094) or selective action in terms of glucose consumption in $\mathrm{C} 2 \mathrm{C} 12$ myocytes (complex VC024 and VC051) to complexes with high activity against all models tested (complex VC107). The results of cytotoxicity tests for the complexes given in Table 2 did not show any significant cytotoxic activity for any of the cell models used in the studies. 
Table 1. Activity profile of selected vanadium complexes in the used cell models. Results were expressed as per cent of activity of BMOV

\begin{tabular}{|l|c|c|c|c|c|c|}
\cline { 2 - 7 } \multicolumn{1}{c|}{} & \multicolumn{2}{c|}{$\begin{array}{c}\text { Glucose utilization } \\
\text { (C2C12 myocytes) }\end{array}$} & \multicolumn{2}{c|}{$\begin{array}{c}\text { Lipid accumulation } \\
\text { (3T3-L1 adipocytes) }\end{array}$} & \multicolumn{2}{c|}{$\begin{array}{c}\text { Insulin secretion } \\
\text { (RINm5F beta-cells) }\end{array}$} \\
\hline Complex & Mean (\%) & SD & Mean (\%) & SD & Mean (\%) & SD \\
\hline VC051 & 170 & 17 & 92 & 25 & 90 & 9 \\
\hline VC024 & 177 & 27 & 99 & 5 & 109 & 12 \\
\hline VC043 & 252 & 13 & 120 & 19 & 89 & 6 \\
\hline VC094 & 104 & 10 & 107 & 22 & 142 & 7 \\
\hline VC107 & 128 & 7 & 135 & 12 & 124 & 11 \\
\hline
\end{tabular}

Table 2. The results of cytotoxicity testing for selected vanadium complexes in the used cell models. Results were expressed as per cent of control containing solvent only; n.t. - not tested.

\begin{tabular}{|l|c|c|c|c|c|c|}
\cline { 2 - 7 } \multicolumn{1}{c|}{} & \multicolumn{2}{c|}{ C2C12 myocytes } & \multicolumn{2}{c|}{ 3T3-L1 adipocytes } & \multicolumn{2}{c|}{ RINm5F beta-cells } \\
\hline Compound & Mean (\%) & SD & Mean (\%) & SD & Mean (\%) & SD \\
\hline BMOV & 91 & 7 & 116 & 1 & 88 & 2 \\
\hline VOSO $_{4}$ & 84 & 7 & 123 & 7 & 89 & 2 \\
\hline ROSIGLITAZONE & 120 & 3 & 120 & 6 & n.t. & n.t. \\
\hline GLIBENCLAMIDE & n.t. & n.t. & n.t. & n.t. & 148 & 8 \\
\hline VC051 & 112 & 8 & 103 & 14 & 98 & 11 \\
\hline VC024 & 125 & 7 & 95 & 11 & 106 & 9 \\
\hline VC043 & 148 & 11 & 99 & 6 & 90 & 6 \\
\hline VC094 & 71 & 16 & 105 & 7 & 86 & 10 \\
\hline VC107 & 98 & 2 & 100 & 21 & 83 & 15 \\
\hline
\end{tabular}

Previously published results concerning anti-diabetic activity of newly synthesized vanadium complexes include studies with a limited number of tested compounds. These studies are usually conducted in animal models, while studies in cell-based models are usually limited to one cellular model. For studies involving tens or hundreds of newly synthesized compounds, this approach is not possible; therefore, a multi-step process of early drug development from initial screening to final in vivo testing only for the most active compounds is the only rational approach. Due to the multidirectional action of vanadium compounds comprising various cells and molecular mechanisms, the most appropriate approach in the assessment of their anti-diabetic action and their impact on metabolism seems to involve several cell models representing different tissues. The approach based on cellular phenotypic screening and used in this study allowed for an effective assessment of the activity of vanadium complexes and confirmed this assumption.

In the next step these compounds were tested in a range of concentrations in the same experimental models for confirmation of the results observed in these preliminary tests. Subsequent studies of other mechanisms of anti-diabetic activity were carried out and profiling of the tested complexes against cells representing the main organs of the target action of compounds with anti-diabetic activity was performed. Based on this set of results, a few vanadium complexes have been selected for in vivo tests.

\section{Conclusions}

The results of this study have allowed the selection of vanadium complexes with a multidirectional anti-diabetic activity, which has facilitated the choice of compounds for further tests in in vitro models. This study provides strong support for the application of screening cell-based assays involving a phenotypic approach for the discovery of novel anti-diabetic drugs from vanadium complexes class.

The tested 110 vanadium complexes are characterized by pronounced heterogeneity of activity profiles related to different cell models (myocytes, adipocytes, beta-cells) associated with pathomechanisms and treatment of metabolic disorders. This indicates interesting prospects for developing new compounds with targeted, desirable cellular activity, important not only in the treatment of metabolic diseases.

\section{Acknowledgement}

This work was partly financed by the European Regional Development Fund under the Innovative Economy Program 2007- 
2013 (WND POIG.01.03.01-174/09). Authors would like to acknowledge all participants for their contribution to this grant. We are very grateful to Professor Barbara Filipek, Professor Marek Stępniewski and Professor Jacek Sapa for helpful consultations and organizational support during conduct this study.

\section{References}

1. Global Health Estimates 2016: Disease burden by Cause, Age, Sex, by Country and by Region, 2000-2016. Geneva, World Health Organization; 2018, https://www.who.int/healthinfo/ global_burden_disease/estimates/en/index1.html

2. Miller BR, Nguyen H, Hu CJ, Lin C, Nguyen QT. New and emerging drugs and targets for type 2 diabetes: reviewing the evidence. American Health \& Drug Benefits. 2014;7(8):45263.

3. Alkhouri N, Poordad F, Lawitz E. Management of nonalcoholic fatty liver disease: Lessons learned from type 2 diabetes. Hepatology Communications. 2018 ;2(7):778-785.

4. Thompson KH, Orvig C. Vanadium in diabetes: 100 years from Phase 0 to Phase I. Journal of Inorganic Biochemistry. 2006;100(12):1925-35.

5. Rehder D. The role of vanadium in biology. Metallomics. 2015;7(5):730-42.

6. Rehder D. The future of/for vanadium. Dalton Transactions. 2013;42(33):11749-61.

7. Shechter Y, Li J, Meyerovitch J, Gefel D, Bruck R, Elberg G, Miller DS, Shisheva A. Insulin-like actions of vanadate are mediated in an insulin-receptor-independent manner via non-receptor protein tyrosine kinases and protein phosphotyrosine phosphatases. Molecular and Cellular Biochemistry. 1995;153(1-2):39-47.

8. Venkatesan N, Avidan A, Davidson MB. Antidiabetic action of vanadyl in rats independent of in vivo insulin-receptor kinase activity. Diabetes. 1991;40(4):492-8.

9. Scior T, Guevara-Garcia JA, Do QT, Bernard P, Laufer S. Why Antidiabetic Vanadium Complexes are Not in the Pipeline of "Big Pharma” Drug Research? A Critical Review. Current Medicinal Chemistry. 2016;23(25):2874-2891.

10. Marín-Peñalver JJ, Martín-Timón I, Sevillano-Collantes C, Del Cañizo-Gómez FJ. Update on the treatment of type 2 diabetes mellitus. World Journal of Diabetes. 2016;7(17):354-95.

11. Inzucchi SE, Bergenstal RM, Buse JB, Diamant M, Ferrannini E, Nauck M, Peters AL, Tsapas A, Wender R, Matthews DR. Management of hyperglycemia in type 2 diabetes, 2015: a patient-centered approach: update to a position statement of the American Diabetes Association and the European Association for the Study of Diabetes. Diabetes Care. 2015;38(1):140-9.

12. Song R. Mechanism of Metformin: A Tale of Two Sites. Diabetes Care. 2016;39(2):187-9.

13. Abrahamson MJ. Should sulfonylureas remain an acceptable first-line add-on to metformin therapy in patients with type 2 diabetes? Yes, they continue to serve us well! Diabetes Care. 2015;38(1):166-9.

14. Patil PD, Mahajan UB, Patil KR, Chaudhari S, Patil CR, Agrawal YO, Ojha S, Goyal SN. Past and current perspective on new therapeutic targets for Type-II diabetes. Drug Design, Development and Therapy. 2017;11:1567-1583.

15. Makinen MW, Salehitazangi M. The Structural Basis of Action of Vanadyl (VO2+) Chelates in Cells. Coordination Chemistry Reviews. 2014;279:1-22.

16. Wu Y, Huang M, Zhao P, Yang X. Vanadyl acetylacetonate upregulates PPAR $\gamma$ and adiponectin expression in differentiated rat adipocytes. Journal of Biological Inorganic Chemistry. 2013;18(6):623-31

17. Niu X, Xiao R, Wang N, Wang Z, Zhang Y, Xia Q, Yang $X$. The Molecular Mechanisms and Rational Design of Anti-Diabetic Vanadium Compounds. Current Topics in Medicinal Chemistry. 2016;16(8):811-22.

18. Missaoui S, Ben Rhouma K, Yacoubi MT, Sakly M, Tebourbi O. Vanadyl sulfate treatment stimulates proliferation and regeneration of beta cells in pancreatic islets. Journal of Diabetes Research. 2014;2014:540242.

19. Gao Z, Zhang C, Yu S, Yang X, Wang K. Vanadyl bisacetylacetonate protects $\beta$ cells from palmitate-induced cell death through the unfolded protein response pathway. Journal of Biological Inorganic Chemistry. 2011;16(5):789-98.

20. Zheng W, Thorne N, McKew JC. Phenotypic screens as a renewed approach for drug discovery. Drug Discovery Today. 2013;18(21-22):1067-73.

21. Wagner BK. The resurgence of phenotypic screening in drug discovery and development. Expert Opinion on Drug Discovery. 2016;11(2):121-5.

22. Hou WL, Yin J, Alimujiang M, Yu XY, Ai LG, Bao YQ, Liu F, Jia WP. Inhibition of mitochondrial complex I improves glucose metabolism independently of AMPK activation. Journal of Cellular and Molecular Medicine. 2018;22(2):13161328.

23. Sun B, Zhong Z, Wang F, Xu J, Xu F, Kong W, Ling Z, Shu N, Li Y, Wu T, Zhang M, Zhu L, Liu X, Liu L. Atorvastatin impaired glucose metabolism in $\mathrm{C} 2 \mathrm{C} 12$ cells partly via inhibiting cholesterol-dependent glucose transporter 4 translocation. Biochemical Pharmacology. 2018;150:108-119.

24. Zhang L, Huang Y, Liu F, Zhang F, Ding W. Vanadium(IV)-chlorodipicolinate inhibits 3T3-L1 preadipocyte adipogenesis by activating LKB1/AMPK signaling pathway. Journal of Inorganic Biochemistry. 2016;162:1-8.

25. Gundhla IZ, Walmsley RS, Ugirinema V, Mnonopi NO, Hosten E, Betz R, Frost CL, Tshentu ZR. pH-metric chemical speciation modeling and studies of in vitro antidiabetic effects of bis[(imidazolyl)carboxylato]oxidovanadium(IV) complexes. Journal of Inorganic Biochemistry. 2015;145:11-8. 26. Zeng XY, Zhou X, Xu J, Chan SM, Xue CL, Molero JC, 
Ye JM. Screening for the efficacy on lipid accumulation in 3T3-L1 cells is an effective tool for the identification of new anti-diabetic compounds. Biochemical Pharmacology. 2012;84(6):830-7.

27. Liu JC, Yu Y, Wang G, Wang K, Yang XG. Bis(acetylacetonato)-oxovanadium(iv), bis(maltolato)-oxovanadium(iv) and sodium metavanadate induce antilipolytic effects by regulating hormone-sensitive lipase and perilipin via activation of Akt. Metallomics. 2013 ;5(7):813-20.

28. Skelin M, Rupnik M, Cencic A. Pancreatic beta cell lines and their applications in diabetes mellitus research. ALTEX. 2010;27(2):105-13

29. Rumora L, Hadzija M, Maysinger D, Zanić-Grubisić T. Positive regulation of ERK activation and MKP-1 expression by peroxovanadium complex bpV (phen). Cell Biology and Toxicology. 2004;20(5):293-301.

30. Leney SE, Tavaré JM. The molecular basis of insulin-stimulated glucose uptake: signalling, trafficking and potential drug targets. Journal of Endocrinology. 2009;203(1):1-18.

31. Vogel HG, Editor. Drug Discovery and Evaluation: Pharmacological Assays. Springer-Verlag, 2013.

32. Burns SM, Vetere A, Walpita D, Dančík V, Khodier C, Perez J, Clemons PA, Wagner BK, Altshuler D. High-throughput luminescent reporter of insulin secretion for discovering regulators of pancreatic Beta-cell function. Cell Metabolism. 2015;21(1):126-37.

33. Porte D, Kahn SE. beta-cell dysfunction and failure in type 2 diabetes: potential mechanisms. Diabetes. 2001;50 Suppl 1:S160-3.

34. Thompson KH, Lichter J, LeBel C, Scaife MC, McNeill JH, Orvig C. Vanadium treatment of type 2 diabetes: a view to the future. Journal of Inorganic Biochemistry. 2009 ;103(4):5548.

35. Conconi MT, DeCarlo E, Vigolo S, Grandi C, Bandoli G, Sicolo N, Tamagno G, Parnigotto PP, Nussdorfer GG. Effects of some vanadyl coordination compounds on the in vitro insulin release from rat pancreatic islets. Horm Metab Res. 2003 Jul;35(7):402-6

36. Yu-Bing Sun, Qing Xie, Wei Li, Yi Ding, Yu-Ting Ye. Synthesis, Crystal Structures, and Insulin Enhancement of Vanadium(V) Complexes Derived From 2-Bromo-N'-(2-hydroxybenzylidene)benzohydrazide, Synthesis and Reactivity in Inorganic, Metal-Organic, and Nano-Metal Chemistry, 46:11, 1613-1617, 